\title{
Gambaran Perawatan Payudara dan Nutrisi Selama Kehamilan Terhadap Produksi ASI Ibu Hamil
}

\author{
Martina Astari \\ Akademi Kebidanan Bunga Bangsaku Bangka
}

Informasi Artikel :

Diterima : 15 April 2021

Direvisi : 02 Mei 2021

Disetujui : 25 Mei 2021

Diterbitkan : 15 Juni 2021

"Korespondensi Penulis : martinaastari89@gmail.com

\begin{abstract}
A B S T R A K
Banyak faktor yang mempengaruhi keberhasilan ini. hasil SDKI 2012 menunjukkan penurunan jumlah bayi yang mendapatkan ASI eksklusif hingga $7,2 \%$. Menyusui adalah proses alami manusia tetapi tidak sederhana seperti yang di bayangkan khalayak umum, Sedangkan di Wilayah Kerja Puskesmas Girimaya Pencapaian angka pemberian ASI Eksklusif sampai dengan 6 bulan didapatkan sebesar $50 \%$ ibu yang lulus ASI Eksklusif. Tujuan penelitian ini adalah untuk mengetahui Gambaran Perawatan Payudara dan Nutrisi Selama Kehamilan terhadap Produksi ASI di Puskesmas Girimaya Kota Pangkalpinang. Desain penelitian ini adalah survey deskriptif dengan populasi semua ibu post partum yang ada di Wilaya Kerja puskesmas Girimaya periode 2021 sampai dengan April 2021 yang berjumlah 62 orang dan sampel diambil dengan tehnik total populasi yaitu 62 orang. Variabel penelitian meliputi variabel independen yaitu perawatan payudara dan asupan nutrisi selama kehamilan dan variabel dependen adalah produksi asi. Data dianalisis dengan analisis univariat didapatkan proporsi responden yang melakukan perawatan payudara lebih besar yaitu 34 orang $(54,8 \%)$ dari responden yang tidak melakukan yaitu 28 orang $(45,2 \%)$. responden dengan nutrisi baik lebih besar proporsinya yaitu sebesar 39 orang $(62,9 \%)$ daripada responden dengan nutrisi kurang yaitu sebesar 23 orang $(37,1 \%)$. Maka disarankan bagi ibu untuk melakukan perawatan payudara selama kehamilan dan nifas.
\end{abstract}

Kata kunci

: ASI, Produksi ASI

\section{ABSTRACT}

Many factors influence this success. The results of the SDKI 2012 showed a decrease in the number of infants who were exclusively breastfed by $7.2 \%$. Breastfeeding is a natural human process but it is not as simple as imagined by the general public, while in the Girimaya Health Center Work Area, the achievement of exclusive breastfeeding rates for up to 6 months is obtained by 50\% of mothers who pass exclusive breastfeeding. The purpose of this study was to determine the description of breast care and nutrition during pregnancy on milk production at the Girimaya Public Health Center, Pangkalpinang City. The design of this study is a descriptive survey with a population of all post partum mothers in the Girimaya Health Center Work Area for the period 2021 to April 2021, which amounted to 62 people and the sample was taken with a total population technique of 62 people. Research variables include independent variables, namely breast care and nutritional intake during pregnancy and the dependent variable is breast milk production. Data were analyzed by univariate analysis, it was found that the proportion of respondents who did breast care was greater, namely 34 people (54.8\%) than respondents who did not, namely 28 people (45.2\%). respondents with good nutrition have a greater proportion of 39 people (62.9\%) than respondents with less nutrition, which is 23 people (37.1\%). So it is recommended for mothers to do breast care during pregnancy and postpartum. 


\section{PENDAHULUAN}

Kesehatan merupakan salah satu aspek dari kehidupan masyarakat. Mutu hidup, produktivitas tenaga kerja, angka kesakitan dan kematian yang tinggi pada bayi dan anak- anak, menurunya daya kerja fisik dan serta terganggunya daya kerja mental adalah akibat langsung dan tidak langsung dari masalah gizi kurang (Siregar, 2018).

Salah satu tujuan pembangunan nasional adalah membangun Sumber Daya Manusia (SDM) yang berkualitas agar mereka dapat melanjutkan perjuangan pembangunan nasional untuk menuju masyarakat sejahtera, adil, dan makmur. Setiap ibu menghasilkan air susu, yang kita sebut air susu ibu (ASI) sebagai makanan alami yang disediakan untuk bayi (Roesli, 2018).

Jumlah ibu menyusui di AS kini kian meningkat. Bahkan mencapai rekor tertinggi dalam 20 tahun terakhir. Sebanyak 3 dari 4 ibu di AS kini menyusui bayi mereka. Demikian hasil laporan badan pemerintah AS, Centers for Disease Control and Prevention (CDC). Laporan terbaru ini didasarkan pada survei federal komprehensif yang melibatkan wawancara langsung dan juga pemeriksaan medis. Temuan ini berdasarkan informasi untuk 434 bayi dari tahun 2005 dan 2006. (Moctar, 2019).

Pemberian air susu ibu (ASI) secara eksklusif dapat menyelamatkan lebih dari 30 ribu balita di Indonesia. Dalam siaran pers yang dikirim UNICEF, jumlah bayi di Indonesia yang mendapatkan ASI eksklusif terus menurun. Menurut Survei Demografi Kesehatan Indonesia, jumlah bayi usia enam bulan yang mendapatkan ASI eksklusif menurun dari 7,9\% menjadi 7,8\%. Sementara itu, hasil SDKI 2007-2012 menunjukkan penurunan jumlah bayi yang mendapatkan ASI eksklusif hingga 7,2\%. Pada saat yang sama, jumlah bayi di bawah enam bulan yang diberi susu formula meningkat dari 16,7\% pada 2002 menjadi $27,9 \%$ pada 2007. UNICEF menyimpulkan, cakupan ASI eksklusif enam bulan di Indonesia masih jauh dari rata-rata dunia, yaitu 38\% (SDKI, 2012).

Perlindungan terhadap penggunaan ASI sebenarnya telah banyak diatur dengan peraturan pemerintah, undang-undang dan kesepakatan Internasional. Mulai UndangUndang Dasar 1945 Pasal 28 ayat (2) butir b, TAP MPR-RI Nomor IV/MPR/1999 tentang GBHN 1999-2004; U.U No. 1 tahun 1951 tentang Perburuhan, U.U. No. 4 tahun 1979 tentang Kesejahteraan AnaK, UU No. 10 Tahun 1992 tentang Perkembangan Kependudukan dan Pembangunan Keluarga Sejahtera; Undang-Undang No. 23 tahun 1992 tentang Kesehatan, U.U. No. 7 Tahun 1996 tentang pangan, Begitu banyaknya aturan yang melindungi penggunaan ASI, tetapi masih saja banyak pelanggaran yang terjadi. Berbagai penyimpangan tersebut seakan tampak di depan mata kita, tetapi sepertinya tidak kuasa dapat melindungi kepentingan generasi penerus bangsa untuk dapat mendapatkan ASI (Prawirohardjo, 2018).

ASI merupakan makanan yang bergizi sehingga tidak memerlukan tambahan komposisi. Disamping itu ASI mudah dicerna oleh bayi dan langsung terserap. Diperkirakan $80 \%$ dari jumlah ibu yang melahirkan ternyata mampu menghasilkan air susu dalam jumlah yang cukup untuk keperluan bayinya secara penuh tanpa makanan tambahan selama enam bulan pertama. Bahkan ibu yang gizinya kurang baik pun sering dapat menghasilkan ASI cukup tanpa tambahan selama tiga bulan pertama (Winjoksastro, 2016).

Dalam masa nifas, pengetahuan tentang perawatan payudara sangat penting untuk diketahui ibu, hal ini berguna untuk menjaga keindahan payudara serta menghindari masalah-masalah dalam proses menyusui. Dalam pelaksanaannya proses menyusui itu tidak mudah, perlu persiapan yang benar benar matang dan perhatian misalnya pada saat hamil ibu harus selalu melakukan perawatan payudara untuk persiapan laktasi karena dengan perawatan payudara yang rutin dipastikan pada saat menyusui kelak 
akan memberikan dampak yang baik bagi produksi ASI, demikian pun pada saat setelah melahirkan atau post partum, dengan perawatan payudara diharapkan penyulit seperti infeksi payudara, bendungan payudara dan keluhan lainnya dapat diatasi dengan baik atau tidak ditemukan (Suryoprajogo, 2012).

Jumlah ibu yang melakukan perawatan payudara selama masa kehamilan dan nifas diketahui belum banyak, hanya sekitar $49 \%$ saja dari ibu hamil yang melakukannya (Puskesmas Girimaya, 2019).

Dari hasil prasurvey di Wilaya Kerja Puskesmas girimaya kegagalan mereka memberikan Asi Ekslusif banyak dikarenakan karena kurangnya produksi ASI ataupun tidak keluar sama sekali, padahal keluhan - keluhan tersebut dapat diatasi dengan perawatan payudara sebelum dan sesudah melahirkan. Perawatan yang biasa dilakukan pada payudara oleh ibu - ibu yaitu dengan membersihkan dengan menggunakan sabun pada saat mandi, serta menggunakan minyak lampu pada putting agar diharapkan bersih dari kotoran, perilaku tersebut adalah salah dan perlu penyuluhan mengenai perawatan payudara yang benar.Berdasarkan dari data dan uraian diatas maka peneliti tertarik untuk melakukan penelitian mengenai "Gambaran Perawatan Payudara dan Nutrisi Selama Kehamilan terhadap Produksi ASI di Wilaya Kerja Puskesmas Girimaya kota Pangkalpinang Tahun 2021".

\section{METODE PENELITIAN}

Penelitian ini merupakan suatu penelitian survey deskriptif dimana suatu metode yang biasanya bertujuan untuk menggambarkan atau memotret masalah kesehatan yang berkaitan dengan kesehatan penduduk atau orang yang tinggal dalam komunitas tertentu (Notoadmodjo, 2018).

Populasi adalah keseluruhan objek penelitian atau objek yang diteliti tersebut. Dalam penelitian ini populasi Ibu Post partum di wilaya kerja puskesmas girimaya dari Januari - April 2021.
Teknik Pengumpulan Data yaitu data primer Data diperoleh dari objek penelitian secara langsung dari hasil pengisian kuesioner yang diberikan pada responden dan Data Sekunder Data sekunder diperoleh dari data-data yang berhubungan dengan penelitian yang ada pada bidan dan Kepala Desa, Dinas Kesehatan, Penelusuran buku sumber data dari internet (Notoadmodjo, 2018).

Instrumen yang digunakan dalam pengumpulan data adalah berupa kuesioner yaitu merupakan pedoman peneliti dalam melakukan wawancara dari responden (Notoadmodjo, 2018).

\section{HASIL PENELITIAN}

\section{Analisis Univariat}

Analisa ini dilakukan untuk mengetahui distribusi frekuensi variabel dependen variabel adapun variabel independen diteliti yaitu (Perawatan payudara dan Nutrisi dalam Kehamilan), dan variabel dependen yaitu ( Produksi ASI). Hasil penelitian terhadap masingmasing variabel akan diuraikan di bawah ini :

Tabel 1 Distribusi Frekuensi Responden Berdasarkan Perawatan payudara terhadap produksi ASI

\begin{tabular}{c|c|c|c}
\hline No & Perawatan Payudara & Frekuensi & $\%$ \\
\hline 1 & Ya & 34 & 54,8 \\
\hline 2 & Tidak & 28 & 45,2 \\
\hline & Jumlah & 62 & 100 \\
\hline
\end{tabular}

Berdasarkan tabel 1 diatas dari 35 responden didapatkan ibu melakukan perawatan payudara sebanyak 34 responden $(54,8 \%)$ dan yang tidak melakukan perawatan payudara yaitu sebanyak 28 responden $(45,2 \%)$.

Tabel 2 Distribusi Frekuensi Responden Berdasarkan nurisi selama kehamilan terhadap produksi ASI 


\begin{tabular}{cccc}
\hline \hline No & Nutrisi Selama hamil & Frekuensi & $\%$ \\
1 & Baik & 39 & 62,9 \\
2 & Kurang & 23 & 37,1 \\
& Jumlah & 62 & 100 \\
\hline
\end{tabular}

Berdasarkan tabel 2 diatas dari 62 responden didapatkan ibu yang nutrisinya baik selama kehamilan sebanyak 39 responden $(62,9 \%)$ dan kurang sebanyak 23 responden $(37,1 \%)$.

\section{PEMBAHASAN}

Penelitian ini menggunakan desain Deskriftif yaitu mengambarkan saja tentang perawatan payudara dan nutrisi terhadap produksi asi, dengan menggunakan UjiSquare serta Pertanyaan sebagai alat yang digunakan untuk mengumpulkan data melalui Angket dan Kuesioner.

Penelitian kali ini dilakukan di Puskesmas Girimaya Kota Pangkalpinang, semua data dikelola dan diambil dari data primer diperoleh secara langsung oleh responden dengan wawancara menggunakan kuesioner. Dan juga data sekunder yaitu data pelaporan pelayanan kesehatan pasien di Puskesmas girimaya, Instansi, internet dan penelusuran literatur lain. Penelitian kali ini menggunakan sampel sebanyak 62 orang responden, dengan pembahasan sebagai berikut :

\section{Perawatan Payudara}

Dari hasil analisa univariat diketahui bahwa proporsi responden yang melakukan perawatan payudara lebih besar yaitu 34 orang $(54,8 \%)$ dari responden yang tidak melakukan yaitu 28 orang $(45,2 \%)$.

Dari penjelasan diatas dapat disimpulkan bahwa responden telah banyak mengetahui dan mengerti akan manfaat perawatan payudara selama kehamilan.

Sedangkan menurut penelitian yang dilakukan oleh Dwiyanti (2009) di Bangsal Mawar I RSUD Dr. Moewardi Surakarta. dari 30 responden diketahui responden yang melakukan perawatan payudara selama kehamilan ataupun pasca melahirkan diketahui sebanyak 78,3\% yang memiliki produksi ASI yang cukup bagi bayinya.

Jumlah ibu yang melakukan perawatan payudara selama masa kehamilan dan nifas diketahui belum banyak, hanya sekitar $49 \%$ saja dari ibu hamil yang melakukannya.

Penelitian yang dilakukan oleh Dwiyanti sama halnya dengan penelitian yang dilakukan oleh Noviani (2016) ibu yang melakukan perawatan payudara sejak masa kehamilan sebanyak $67 \%$ yang memiliki produksi ASI yang cukup baik sedangkan yang tidak melakukan perawatan payudara sebanyak $43 \%$.

Menurut desi aprianti (2019) seorang ibu yang sering melakukan perawatan payudara produksi ASI nya lebih baik di bandinkan ibu yang tidak melakukan perawatan payudara.

peneliti kali ini sama seperti yang di lakukan oleh peneliti yang di lakukan kali ini di Poskesdes Jemenang dimana banyak ibu yang melakukan perawatan payudara, ini dikarenakan pengetahuan baik responden yang mereka dapatkan dari media ataupun penyuluhan dari petugas kesehatan itu sendiri.

Seperti diketahui Pengetahuan merupakan faktor predisposisi terjadinya perilaku Dari pengalaman dan penelitian terbukti bahwa perilaku yang didasari oleh pengetahuan akan lebih langgeng dari pada perilaku yang tidak didasari oleh pengetahuan.

Persiapan dini sejak masa kehamilan hingga menyusui sangat membantu kelancaran proses menyusui secara keseluruhan. Praktek menyusui yang baik dan benar setiap ibu perlu mempelajarinya, bukan pada ibu yang pertama kali hamil dan melahirkan tetapi juga ibu - ibu yang melahirkan anak yang ke 2 dan seterusnya.

Hal ini sesuai Menurut Subianto (2019) perawatan payudara adalah suatu kegiatan yang dilakukan secara sadar dan teratur untuk memeliharan kesehatan 
payudara waktu hamil dengan tujuan untuk mempersiapkan laktasi pada waktu post partum. Perawatan payudara sangat penting dilakukan selama hamil sampai masa menyusui. Hal ini karena payudara merupakan satu-satunya penghasil ASI yang merupakan makanan pokok bayi yang baru lahir sehingga harus dilakukan sedini mungkin.

Penggunaan ASI telah dideklarasikan sebagai gerakan nasional yang merupakan upaya peningkatan derajat kesehatan ibu dan anak. Untuk mencapai keberhasilan gerakan nasional perlu didukung oleh peran serta seluruh anggota masyarakat para ibu sebagai pelopor peningkatan kualitas sumberdaya Indonesia. Peranan petugas kesehatan sangat penting dalam melindungi, meningkatkan, dan mendukung usaha menyusui baik sebelum, selama maupun setelah kehamilan dan persalinan.

\section{Nutrisi Selama Kehamilan}

Dari analisa univariat diketahui bahwa responden dengan nutrisi baik lebih besar proporsinya yaitu sebesar 39 orang $(62,9 \%)$ daripada responden dengan nutrisi kurang yaitu sebesar 23 orang $(37,1 \%)$. Dapat disimpulkan telah banyak ibu - ibu hamil yang memiliki kecukupan gizi, hal ini dikarenakan mereka telah sadar akan pentingnya gizinya yang baik bagi pertumbuhan dan perkembangan janinnya.

Sedangkan menurut penelitian yang dilakukan Rani susanti (2018) produksi ASI juga di penggaruhi oleh asupan nutrisi ibu selama kehamilan karna nutrisi ibu sangat berpengaruh terhadap perkembangan payudara.

Penelitian yang di lakukan oleh Rani susanti sama hal nya di lakukan oleh Suharyono (2018) keberhasilan laktasi dipengaruhi oleh kondisi sebelum dan saat kehamilan. Kondisi sebelum kehamilan ditentukan oleh perkembangan payudara saat lahir dan saat pubertas.
Penjelasan Suharyono tersebut terbukti pada penelitian yang dilakukan kali ini di Poskesdes Jemenang ibu dengan nutrisi yang baik mempunyai produksi ASI yang baik dan cukup. Ini dikarenakan dengan pertambahan usia kandungan, maka kebutuhan gizi ibu hamil akan meningkat, terutama setelah memasuki kehamilan trimester kedua. Sebab pada saat itu, pertumbuhan janin berlangsung pesat - terutama perkembangan otak dan susunan syaraf - dan membutuhkan asupan gizi yang optimal sehingga membuat nafsu makan ibu bertambah yang berimbas pada peningkatan gizi ibu.

Hal ini sesuai dengan teori Menurut Suharyono (2018) pada saat kehamilan yaitu trimester II payudara mengalami pembesaran karena pertumbuhan dan difrensiasi dari lobuloalveolar dan sel epitel payudara. Pada saat pembesaran payudara ini hormon prolaktin dan laktogen placenta aktif bekerja yang berperan dalam produksi ASI.

Gizi dan Nutrisi ibu hamil merupakan hal penting yang harus dipenuhi selama kehamilan berlangsung. Resiko akan kesehatan janin yang sedang dikandung dan ibu yang mengandung akan berkurang jika ibu hamil mendapatkan gizi dan nutrisi yang seimbang. Oleh karena itu, keluarga dan ibu hamil haruslah memperhatikan mengenai hal ini. Gizi atau nutrisi ibu hamil kondisinya sama saja dengan pengaturan gizi mengenai pola makan yang sehat.

\section{KESIMPULAN}

Berdasarkan hasil penelitian mengenai gambaran tentang perawatan payudara dan nutrisi selama kehamilan terhadap produksi asi yang telah dilakukan dan pembahasan yang dikemukakan dapat ditarik kesimpulan sebagai berikut: Dari hasil analisa univariat bahwa proporsi responden yang melakukan perawatan payudara lebih besar yaitu 34 orang $(54,8 \%)$ dari responden yang tidak melakukan yaitu 28 orang $(45,2 \%)$. Dari hasil analisa univariat proporsi responden dengan 
nutrisi baik lebih besar proporsinya yaitu sebesar 39 orang $(62,9 \%)$ daripada responden dengan nutrisi kurang yaitu sebesar 23 orang $(37,1 \%)$.

\section{DAFTAR PUSTAKA}

Manuaba, IBG (2005). Ilmu Kebidanan Penyakit Kandungan dan Keluarga Berencana Untuk Pendidikan Bidan, Jakarta : EGC.

Masdanang (2008). Deteksi Dini Terhadap Komplikasi Kehamilan. Terdapat dalam (http://www.masdanang.blogspot.co.cc ).

Mochtar, Rustam (2019). Sinopsis Obstetri. EGC : Jakarta.

Notoadmodjo, Soekidjo (2018), Pendidikan dan Perilaku Kesehatan, Jakarta : Rineka Cipta( 2005 ), Metodelogi Penelitian Kesehatan, Jakarta : RinekaCipta.

Prawihardjo, Sarwono ( 2018 ), Buku Acuan Nasional Pelayanan Kesehatan Maternal dan Neonatal, Jakarta : Tri Dasa Printer.

Ramaiah (2017). Faktor-faktor penyebab rendahnya pemberian ASI eksklusif. Dikutip luluvikar.files.wordpress.com.

Roesli (2018). Pelaksanaan Inisiasi Menyusui Dini di Klinik-Klinik Bersalin di Kecamatan Johan Pahlawan Kabupaten Aceh Barat. Dikutip di http://repository.usu.ac.id/bitstrea diakses pada tanggal 16 Jan 2021.

Siregar, Arifin (2014). Pemberian ASI Ekslusif dan Faktor - factor yang Mempengaruhinya. FKM : USU Sedjaoetama, Djaeni Ahmad, (2004) Ilmu Gizi II, FKM : USU.
Suryoprajogo, Nadine (2019), Keajaiban Menyusui, Yogjakarta : Keyword.

Winjoksastro, Hanafi ( 2015 ), Ilmu Kebidanan, Jakarta : Yayasan Bina Pustaka 
